\section{Automated grading of research performance clearly fails to measure up}

\section{SIR - More contentious than national} rankings of research quality, as shown, for example, by David A. King (Nature 430, $311-316 ; 2004)$, is the application of such measures to research institutions. Several leading organizations - such as Thomson Scientific (formerly Thomson ISI), the centres for science and technology studies in Leiden (CWTS) and Bern (CEST) and European bibliometric analysts (see A. F J. van Raan Scientometrics 62, 133-143; 2005) - have emphasized the risk of reaching erroneous condusions through using inappropriate data.

We have compared an automated and a manual analysis of the performance, between 1994 and 2003 of two European national organizations: the UKMedical Research Council (MRC) and the French biomedical research agency (INSERM) in France. The two agencies are both devoted to biomedical research and are of comparable size.

We first used Thomson Scientific's Web of Science, which correctly identified all 17,829 publications from the MRC and all 46,978 from INSERM. We then compared the Essential Science Indicators (ESI) from the Thomson ranking with a manually extracted list of the 'top $1 \%$ ' of publications affiliated to France and Britain.

The results turn out to be very different. The manual analysis took affiliations into account carefully, whereas the automated index missed many INSERM-affiliated papers. ESI rankings show 253 'top 1\%' publications for the MRC and 117 for INSERM, whereas the manual count has the two organizations on a more equal footing, with 513 top $1 \%$ publications for the MRC and 535 for INSERM. As many as $50 \%$ of the MRC's and $80 \%$ of INSERM's highly cited publications are not identified by the automatic extraction.

Given the use to which these figures are put by funding agencies and governments, these discrepancies, and discrepancies in other types of citation studies, emphasize the problems that can arise from the use of bibliometric analyses.

It is important to ensure that affiliations are captured correctly before performing an analysis, and to use the appropriate citation measure.

For both the MRC and INSERM, only about $20 \%$ of papers published in highimpact journals are in the 'highly cited' category, demonstrating that the two indicators should not be confounded.

The research organization of France is extremely complex, which renders assessment difficult. But we believe that
France and other countries must collaborate and reach agreement on benchmarks for assessment of research performance, including a simplified, generally accepted affiliation nomenclature.

N. Haeffner-Cavaillon, C. Graillot-Gak, C. Bréchot

Cellule de Bibliamétrie, Département de

I'Évaluation Scientifique, INSERM,

101 rue de Tolbiac, 75654 Paris Cedex 13, France

\section{Animal-rights zealots put wild life welfare at risk}

SIR - Your Editorial calling for government resistance to intimidation from animal-rights lobbyists ( ${ }^{\alpha}$ Taking a stand on animal-rights violence" Nature 438, 1;2005) provides timely advice for researchers too, as our public scientific meetings are increasingly attracting disruptive protest if they involve animal research.

In October I participated in the annual scientific meeting of the Royal Zoological Society of New South Wales. The focus was on the challenges of managing the impacts of over-abundant animals and pest species that threaten Australias biodiversity and economy. These meetings are open to the public, and discussion is encouraged.

But the $\mathbf{2 0 0 5}$ forum was systematically and strategically sabotaged by animal-rights lobbyists from at least six organizations. They monopolized question time and plenary discussion sessions with prepared speeches and interjections, all pushing a short-sighted single-issue agenda.

They were preaching to the converted about the fundamental need for animal welfare, as all who attended the forum share a concern for the protection of Australia's unique wildlife and environment. And by strangling discussion and learning among the very people charged with looking after Australiass wildlife and agriculture, these lobbyists did not help their primary cause: reducing the killing of animals by humans.

Many novel ideas on how to manage pest impact while minimizing the need for direct control were entirely lost in a flood of rhetoric that all animals should live. Yet this right to life apparently does not include those animals that are maimed, killed, displaced or even driven to extinction by the over-abundant pests that continue to plague Australia. Such animals were overlooked by these zealots with their 'let it be' approach to conservation.

This was a great opportunity lost. It sends a grim warning to other scientific societies and researchers hoping to exchange ideas in open forums about animal-related issues.

Peter B. Banks

School of Biological, Earth and Ervironmental Sciences, University of New South Wales, Kensington, New South Wales 2052, Australia

\section{Evaluation bias hits women who aren't twice as good}

SIR - In your Editorial "All things equal" (Nature 437, 296; 2005) and Special Report "Small steps towards campus child care" (Nature 437, 446-447; 2005), much was made of the need for women scientists to have access to good child care if they are to succeed. However, this recent attention to child care in the scientific workplace merely addresses a symptom, rather than a cause, of under-representation of women in science.

Childless women and those with children have strikingly similar patterns of salary disparity and lag in achieving tenure and promotion compared with men.

As your report highlights, nations differ in child-care facilities - but they all share a shortage of women scientists, particularly at higher levels. Furthermore, the proportion of women in different sub-disciplines varies dramatically, but child-care availability is no different for a microbiologist or an engineer.

We suggest that lying behind the paucity of women in science is an unconscious bias in evaluating the sexes. Research shows that both men and women tend to overrate men and underrate women in competence, particularly when women are in a nontraditional field such as science (V. Valian Why So Slow? MIT Press, Cambridge, MA, 1998). For example, when the heads of 147 psychology departments were sent fictitious resumés of prospective faculty members and asked to name the rank — assistant, associate or full professor - to which the candidate would be appointed in their department, the recommended rank was higher if the resumé had a male name than if the same qualifications had a woman's name attached (L. S. Fidell in Woman: Dependent or Independent Variable? 774-782, eds R. K. Unger and F. L. Denmark, Psychological Dimensions, New York, 1975).

More recently, women had to produce twice as many scientific papers of equivalent quality as men to be considered equally competent in a Swedish Medical Research Fellowship postdoctoral programme (C. Wenners and A. Wold Nature 387, 341-343; 1997).

Marlene Zuk ${ }^{\star}$, Gunilla Rosenqvist|

*Department of Biology, University of California, Riverside, California 92521, USA

†Department of Biology, Norwegian University of Science and Technology,

N-7491 Trondheim, Norway

\footnotetext{
Contributions to Correspondence may be submitted to corres@nature.com.They should be nolonger than $\mathbf{5 0 0}$ words, and ideally shorter. They should be signed by no more than three authors; preferably by one. Published contributions are edited.
} 